\title{
The microaerophilic flagellate Giardia intestinalis: Allium sativum (garlic) is an effective antigiardial
}

\author{
Janine C. Harris, ${ }^{1}$ Sue Plummer, ${ }^{2}$ Michael P. Turner $^{1}$ and David Lloyd ${ }^{1}$
}

Author for correspondence: Janine C. Harris. Tel: +44292087 6350. Fax: +442920874305.

e-mail: harrisjc@cf.ac.uk

1 Microbiology Group, School of Biosciences (BIOSI Main Building), Cardiff University, Cardiff CF10 3TL, UK

2 Cultech Biospeciality Products, York Chambers, York Street, Swansea SA1 3NJ, UK

\begin{abstract}
Whole garlic (Allium sativum L.) extract and some of its components were assayed for antigiardial activity. Whole garlic extract gave an $\mathrm{IC}_{50}$ at $24 \mathrm{~h}$ of $0.3 \mathrm{mg} \mathrm{ml}^{-1}$. Most of the components assayed were inhibitory to the organism, especially allyl alcohol and allyl mercaptan, with $\mathrm{IC}_{50}$ values of $7 \mu \mathrm{g} \mathrm{ml}^{-1}$ and $37 \mu \mathrm{g} \mathrm{ml}^{-1}$ respectively. Studies with calcofluor white indicated that whole garlic and allyl alcohol collapse the transmembrane electrochemical membrane potential $(\Delta \psi)$ of the organism, as indicated by uptake of the fluorochrome. Electron microscopy allowed the morphological changes that occur with garlic inhibition to be recorded. Both the surface topography and internal architecture of the organism changed during incubation with the biocides. Both whole garlic and allyl alcohol resulted in fragmentation of the disc and an overexpression of disc microribbons, internalization of flagella, vacuole formation and an increase in distended vesicles. Allyl mercaptan, however, only gave an increase in distended vesicles, suggesting that this biocide has a different mode of action.
\end{abstract}

Keywords : allyl alcohol, allyl mercaptan, protozoan, calcofluor white

\section{INTRODUCTION}

The microaerophilic flagellate parasitic protozoon Giardia intestinalis is the most commonly diagnosed cause of waterborne diarrhoea in the USA and a major problem worldwide (Lengerich et al., 1994). Not only are the transmissible cysts viable in cold water for several months (Bingham et al., 1979) but animals such as voles, muskrats and birds act as reservoirs for humanpathogenic strains (Davies \& Hibler, 1979). Following ingestion, the acidic $\mathrm{pH}$ of the stomach stimulates excystation and the released trophozoites rapidly multiply and colonize the microvillous surface of the jejunum. This can lead to endothelial dysfunction, malabsorbtion of essential nutrients, nausea, diarrhoea, abdominal distension, cramps, and weight loss. In the young, elderly and immunocompromised this can lead to morbidity and even death (Shukry et al., 1986).

The current treatments of choice are either one of a

Abbreviations: NOS, nitric oxide synthase; iNOS, calcium-independent nitric oxide synthase; XTT, 2,3 bis (2-methoxy-4-nitro sulphophenyl)5 [(phenylamino) carbonyl]-2H tetrazolium; see Table 1 for abbreviations of garlic components. family of nitroimidazoles (usually metronidazole), nitrofurans, quinacrine or paromomycin. However, all of these are reported to have unpleasant side effects, and potential carcinogenic, teratogenic and embryogenic questions are being addressed (Friedman, 1980; Davidson, 1990). More importantly, the strains and clones of G. intestinalis show variable sensitivity to the treatments (Majewska et al., 1991), and resistant strains are increasingly developing.

The use of garlic, Allium sativum L., as a medicinal plant predates written history, and its use in gastrointestinal medicine is noted in the Hippocratic writings, by Galen and Dioscorides. Garlic has been shown to be antibacterial (Sharma et al., 1977), antiviral (Fenwick \& Hanley, 1985) and antifungal (Yamada \& Azuma, 1977), as well as possessing both antitumour (Milner, 1996) and antithrombotic (Kiesewetter et al., 1993) properties. Traditionally, the sulphur compound allicin was thought to be responsible for these properties; however, pharmacokinetic studies on allicin show that its half-life in vivo may be too short to account for the activity seen in vitro (Lawson \& Wang, 1993). Increasingly, attention is being focused on the smaller metabolic breakdown products of this molecule. In the urine the most common 
components found after ingestion of garlic are diallyl disulphide and diallyl sulphide (Bartzatt et al., 1992), whilst the most common component found in the blood after ingestion is allyl mercaptan (Xu \& Cho, 1999; Koch, 1996). Garlic is a very complex compound consisting not only of allyl components but many other components, some of which, kaempferol and quercetin, have been shown to have antigiardial activity in vitro (Calzada et al., 1998; Leighton et al., 1993).

The use of garlic and some of its components as antiprotozoals has already been investigated by some authors. Mirelman et al. (1987) investigated the use of allicin on Entamoeba histolytica, Soffar \& Mohktar (1991) assessed its use as an antigiardial alongside its use as an antihelminthic in a selection of patients, whilst Lun et al. (1994) looked at the effect of diallyl trisulphide on Entamoeba histolytica, G. intestinalis and trypanosomes.

The aim of this work was to establish and quantify the antigiardial activity in a freeze-dried garlic extract and to assess the inhibitory activity of commercially available sulphur metabolites of garlic.

\section{METHODS}

Materials. Freeze-dried garlic is a product of Cultech Biospeciality Products, Swansea, UK. Fetal calf serum was supplied by GibcoBRL, through Life Technologies. Dipropyl disulphide, dimethyl disulphide, allyl methyl sulphide, methyl propyl sulphide, allyl alcohol and allyl mercaptan were supplied by Lancaster Synthesis, Morecambe, Lancashire, UK. Fluorescent probes were from Molecular Probes through Cambridge Biosciences. All other chemicals were supplied by Sigma-Aldrich-Fluka.

Cultures. Giardia intestinalis Portland-1 strain ATCC 30888, originally described by Meyer (1976), was a gift of Michael R. Edwards, University of New South Wales, Sydney, Australia. Trophozoites were cultured axenically and anaerobically in screw-capped Nunclon tubes (Life Technologies) at $37^{\circ} \mathrm{C}$ on Diamond's modified TYI-S-33 medium (Edwards et al., 1989), supplemented with $10 \%(\mathrm{v} / \mathrm{v})$ heat-inactivated fetal calf serum. Subculturing was performed routinely at $48 \mathrm{~h}$ intervals by replacing the spent medium without detaching the monolayer. Cells were harvested by replacing the spent medium with fresh, chilling on ice for $20 \mathrm{~min}$, and inverting gently to detach the monolayer. Cells were counted on a haemocytometer slide using $0.4 \%(\mathrm{w} / \mathrm{v})$ trypan blue as a viability indicator; typically this gave cell numbers of $2 \times 10^{6} \mathrm{ml}^{-1}$.

Whole garlic preparation. All garlic extract was made up to the required concentration $(\mathrm{w} / \mathrm{v})$ in appropriate sterile media. Freeze-dried garlic/medium suspension was vortexed for $10 \mathrm{~min}$, left at room temperature for $30 \mathrm{~min}$, centrifuged at $3900 \mathrm{~g}$ for $10 \mathrm{~min}$ to leave a clear supernatant, then filtersterilized by passage through a $0 \cdot 2 \mu \mathrm{m}$ Millipore filter. All components were made up at $5 \mathrm{mg} \mathrm{ml}^{-1}$ in media and filtersterilized before use. Standard concentration ranges were made by serial dilutions in media containing $10 \%$ fetal bovine serum.

Biocide inhibition. Stock solutions of $5 \mathrm{mg} \mathrm{ml}^{-1}$ were made in the appropriate medium (if the compound was insoluble, a suspension was used). A concentration range of $0-2.5 \mathrm{mg} \mathrm{ml}^{-1}$ was established in the reaction vessels by serial dilution. Tubes were inoculated with trophozoites and incubated at $37^{\circ} \mathrm{C}$ for $24 \mathrm{~h}$. After this period the tubes were chilled for $20 \mathrm{~min}$ and the attached trophozoites were detached by gentle inversion. The number of viable cells was determined using trypan blue and haemocytometer counts. Criteria for viability were motility and dye exclusion.

Biocide inhibition using formazan production as viability criterion. The assessment of antigiardial compounds using the soluble tetrazolium XTT (2,3-bis(2-methoxy-4-nitrosulphophenyl)-5[(phenylamino)carbonyl $-2 \mathrm{H}$ tetrazolium) was discussed by Wright et al. (1992). The test sample was added to a 96-well plate (flat-bottomed, well diameter $6.4 \mathrm{~mm}$, well volume $370 \mu \mathrm{l}$ ), in $150 \mu \mathrm{l}$ medium at the required concentration. Culture was added to a final volume of $300 \mu \mathrm{l}$ and the plate was sealed and incubated at $37^{\circ} \mathrm{C}$ for $24 \mathrm{~h}$. After this period, $250 \mu$ l of the medium was carefully removed from the centre of each well, to avoid detachment of the trophozoites, and replaced with $250 \mu \mathrm{l} 0 \cdot 01 \mathrm{M}$ phosphate-buffered saline (PBS), pH 7·2, containing $1 \mathrm{mg}$ glucose $\mathrm{ml}^{-1}$. The plate was incubated for $1 \mathrm{~h}$ at $37^{\circ} \mathrm{C}$ to allow reattachment of any detached trophozoites. Finally, $250 \mu \mathrm{l}$ PBS was removed and replaced with $100 \mu \mathrm{l}$ PBS containing $0 \cdot 2 \mathrm{mg} \mathrm{XTT} \mathrm{ml}^{-1}$. The plates were incubated as previously for $4 \cdot 5-5 \mathrm{~h}$ for the colour to develop and then the $A_{450}$ was measured using a Thermomax microplate reader (Molecular Devices).

Ultraviolet microscopy. Trophozoites were harvested by chilling on ice for $20 \mathrm{~min}$ and inverting to detach the monolayer, and washed with $0 \cdot 01 \mathrm{M} \mathrm{PBS}, \mathrm{pH} 7 \cdot 2$, containing $1 \mathrm{mg}$ glucose $\mathrm{ml}^{-1}$, at $37^{\circ} \mathrm{C}$, to remove the medium. To $0.5 \mathrm{ml}$ of culture, $10 \mu \mathrm{l}$ of a $1 \mathrm{mg} \mathrm{ml} \mathrm{m}^{-1}$ solution of calcofluor white M2R, 4,4'-bis(4 anilino-bis-diethylamino-5-triazin-2lyamino)-2,2'-stilbene disulphonic acid (disodium salt), a fluorescent viability indicator (Fischer et al., 1985; Berglund et al., 1987) was added. The cells were incubated for $15 \mathrm{~min}$ at $37^{\circ} \mathrm{C}$ with the probe and then viewed under ultraviolet light using a Olympus $\mathrm{BH} 2$ triocular ultraviolet microscope. Images were recorded using 400 ISO Fuji Colour, daylight, 38 mm film.

Scanning electron microscopy. Cells washed with PBS containing $1 \mathrm{mg}$ glucose $\mathrm{ml}^{-1}$ were fixed in cacodylate buffer $\mathrm{pH}$ 6.9 containing $1 \%$ paraformaldehyde and $2 \%$ glutaraldehyde, at $4{ }^{\circ} \mathrm{C}$ for $1 \mathrm{~h}$. They were post-fixed with buffered $1 \%$ osmium tetroxide at $4^{\circ} \mathrm{C}$ for $1 \mathrm{~h}$. The cells were dehydrated with successive washes of ethanol. A small drop was sandwiched between two coverslips and placed into a criticalpoint dryer (Balzers CPD 030). All the ethanol was replaced by liquid $\mathrm{CO}_{2}$, which was then removed by increasing the temperature and pressure to $40{ }^{\circ} \mathrm{C}$ and $80 \mathrm{kPa}$ for $45 \mathrm{~min}$. The coverslips were cut with a diamond knife and mounted onto aluminium stubs and sputter coated (Edwards Sputter Coater S150B) with gold. Images were obtained using a JEOL 5200 LV scanning electron microscope.

Transmission electron microscopy. Cells washed with PBS containing $1 \mathrm{mg}$ glucose $\mathrm{ml}^{-1}$ were fixed in cacodylate buffer pH 6.9 containing $1 \%$ paraformaldehyde and $2 \%$ glutaraldehyde, at $4{ }^{\circ} \mathrm{C}$ for $1 \mathrm{~h}$. They were post-fixed with buffered $1 \%$ osmium tetroxide at $4{ }^{\circ} \mathrm{C}$ for $1 \mathrm{~h}$. The cells were dehydrated with successive washes of ethanol. The cell pellet was then embedded into Spurr resin and ultrathin sections obtained using an LKB Ultratome III. The sections were mounted onto $0.5 \%$ Pioloform (in chloroform) coated copper grids and stained using lead citrate and aqueous uranyl 
acetate. Sections were viewed using a JEOL 1210V transmission electron microscope.

\section{RESULTS}

\section{Biocide inhibition of G. intestinalis}

The inhibitory capacity of the whole garlic preparation and the commercially available garlic components were assayed using XTT reduction and trypan blue exclusion.

XTT is often used to assess the respiratory activity and viability of micro-organisms. The tetrazolium salt readily dissolves in $0 \cdot 01 \mathrm{M} \mathrm{PBS,} \mathrm{pH} 7 \cdot 2$, and is taken up by the test organism. The XTT is reduced to the soluble formazan, XTF. The exact sites of reduction are not known but it is proposed that reduction occurs at $\mathrm{NADH}$ and succinate dehydrogenases (Smith \& McFeters, 1997). XTT is used in preference to other
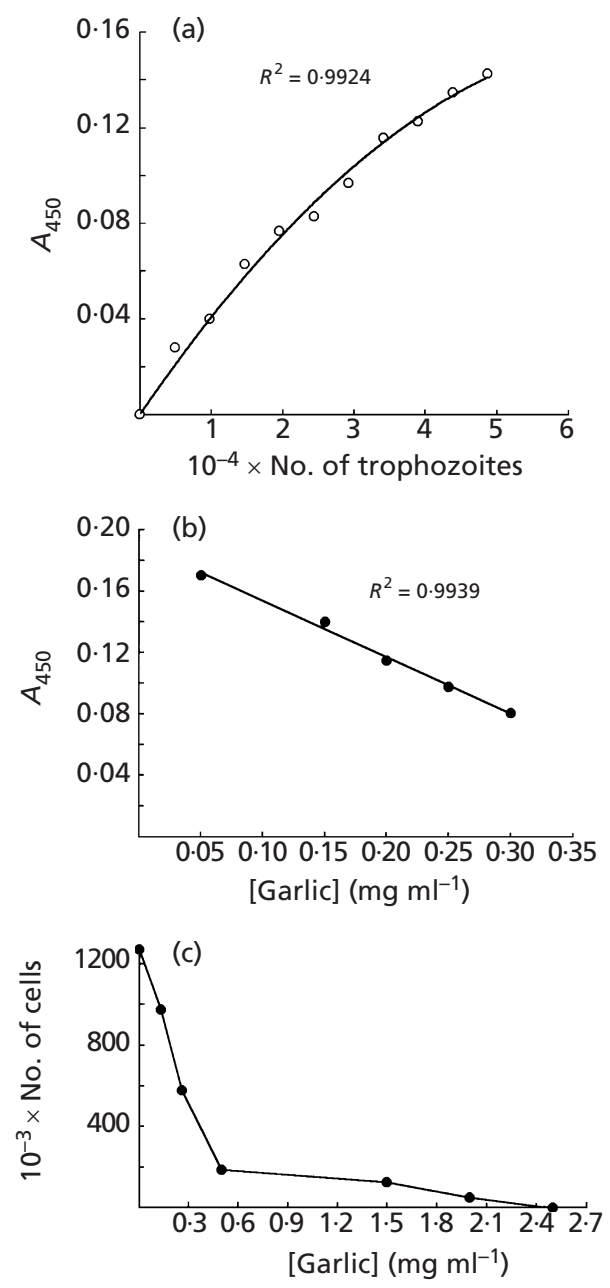

Fig. 1. Inhibition of $G$. intestinalis by whole garlic preparation. (a) Standardization of cell numbers with XTT reduction (Wright et al., 1992). (b) Assay of inhibitory capacity of whole garlic preparation using the method of Wright et al. (1992). (c) Assay of inhibitory capacity of whole garlic preparation using trypan blue exclusion and motility as indicators of viability. The data are means of three replicates.
Table 1. Antiprotozoal activity of whole garlic preparation and various garlic components

\begin{tabular}{|ll|}
\hline Component & $\mathrm{IC}_{\mathbf{5 0}}\left(\mathrm{mg} \mathrm{m}^{-\mathbf{1}}\right)^{*}$ \\
\hline Whole garlic (WG) & $0 \cdot 30$ \\
Methyl propyl sulphide (MPS) & $0 \cdot 25$ \\
Allyl methyl sulphide (AMS) & $0 \cdot 55$ \\
Diallyl sulphide (DAS) & $1 \cdot 30$ \\
Methyl sulphide (MS) & $1 \cdot 30$ \\
Diallyl disulphide (DAD) & $0 \cdot 10$ \\
Dimethyl disulphide (DMD) & $0 \cdot 20$ \\
Methyl propyl disulphide (MPD) & $0 \cdot 30$ \\
Dipropyl disulphide (DPD) & $0 \cdot 45$ \\
Allyl alcohol (AA) & $0 \cdot 007$ \\
Allyl mercaptan (AM) & $0 \cdot 037$ \\
\hline
\end{tabular}

* Mean of three replicates. $\mathrm{IC}_{50}$ taken at $24 \mathrm{~h}$.

tetrazolium salts (CTC, MTT) because the formazan does not have to be stabilized before analysis. Instead the soluble formazan is released as an orange-pink solution which can be analysed at $450 \mathrm{~nm}$. Standardization was easily achieved by addition of known numbers of viable cells to the wells and adding the XTT as described in Methods. Production of XTF correlated with viable cell numbers (Fig. 1a).

Incubation of $G$. intestinalis trophozoites with a range of concentrations $\left(0-0.3 \mathrm{mg} \mathrm{ml}^{-1}\right)$ of whole garlic preparation resulted in inhibition. As the concentration of garlic increased, the reduction of the tetrazolium salt decreased. This could be observed visually by a noticeable colour change and by measuring production of formazan at $450 \mathrm{~nm}$. This correlated with a decrease in viable trophozoites. The calculated $\mathrm{IC}_{50}(50 \%$ inhibitory concentration) at $24 \mathrm{~h}$ was $0.29 \mathrm{mg} \mathrm{ml}^{-1}$. The inhibition appeared to be linear and dose-dependent $\left(R^{2} 0.9939\right)$ (Fig. 1b). Upon evaluation, this method appears ideal for high-throughput screening of numerous antigiardials. However, for the small number of components tested here, it is time consuming and expensive. In preference, analysis of the various commercially available compounds was assayed using trypan blue exclusion, motility and haemocytometer counts as indicators of viability. Analysis of whole garlic preparation using trypan blue gave an $\mathrm{IC}_{50}$ at $24 \mathrm{~h}$ of $0.3 \mathrm{mg} \mathrm{m}^{-1}$, indicating that the two methods correlate (Fig. 1c).

Many components of garlic, such as allicin, alliin, ajoene and vinyl dithiins (the compounds believed to be responsible for the properties of garlic) are not readily available as stable commercial compounds. However, many of the smaller products of allicin metabolism and garlic ingestion are available. Assessment of the inhibitory activity of these compounds is shown in Table 1. These results show that the sulphides, MPS $>$ AMS $>$ DAS,MS, and the disulphides, DAD $>$ DMD $>$ MPD > DPD, are actively inhibitory against $G$. intestinalis. The small compounds, allyl alcohol and allyl mercaptan, neither of which contains the 

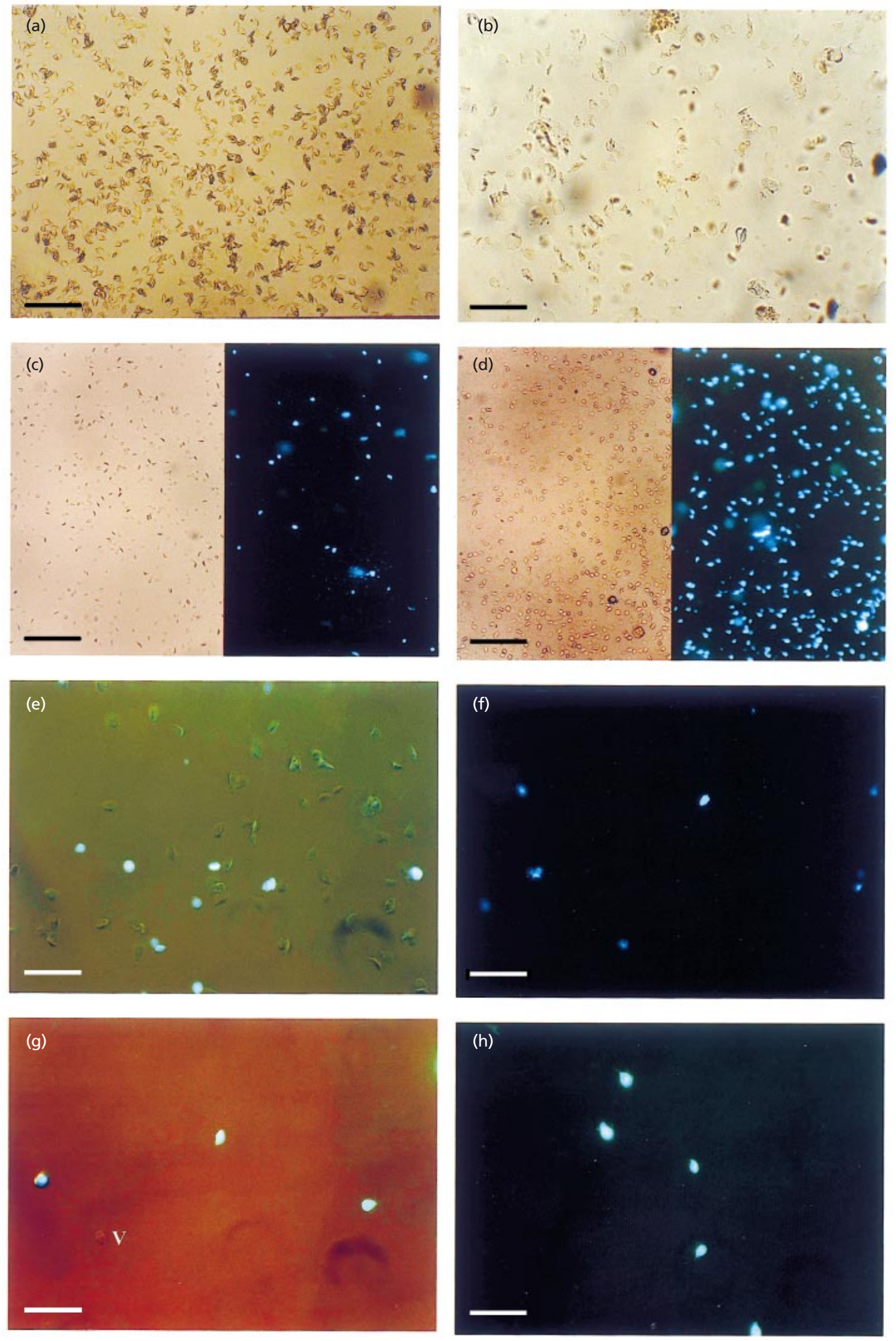
$\mathrm{S}-(=\mathrm{O}) \mathrm{S}$ bond, are very inhibitory, with $\mathrm{IC}_{50}$ values of 0.007 and $0.037 \mathrm{mg} \mathrm{ml}^{-1}$, respectively. Overall the spectrum of activity can be represented as AA $>$ AM $\gg$ DAD $>$ DMD $>$ MPS $>$ WG, MPD $>$ DPD $>$ AMS $\gg$ DAS,MS.

\section{Ultraviolet microscopy}

Ultraviolet fluorochromes are often used to assess the viability of micro-organisms visually, as intracellular and membranous changes can be observed using the naked eye. Using normal visible light microscopy, viable Giardia cells are shaped like a tear drop. They reflect light and are motile, swimming in a distinct spiral pathway. Often they attach to the glass slide but the motion of the flagella can still be observed (Fig. 2a).

Addition of whole garlic preparation resulted in a loss of adherence to the glass slide, and a loss of motility and flagellar movement. This effect increased with increased concentration of biocide. There was also a decrease in cell numbers and an increase in the proportion of swollen, misshapen cells, which had lost osmoregularity (Fig. 2b). Addition of allyl alcohol brought about the same visible changes but much more rapidly and at very low concentrations (not shown).

Many anionic (dead-cell stains) and cationic (live-cell stains) fluorochromes are available. The most commonly used are oxonol $\left[\mathrm{DiBAC}_{4}(3)\right]$, an anionic deadcell stain, and rhodamine 123, a cationic live-cell stain. When dealing with viable cells it is often preferred to use anionic fluorochromes, as cationic fluorochromes may be toxic to the cells and live cells may have an active efflux mechanism to remove the fluorochrome. Calcofluor white $\mathrm{M} 2 \mathrm{R}$ is a fluorescent brightener used in detergents. However, it can also be used as an indicator of cell viability (Fischer et al., 1985; Berglund et al., 1987). This fluorochrome mainly binds to cellulose, chitin callose, carboxylated polysaccharides and $\beta$ linked polymers. Viable cells have an electrochemical potential $(\Delta \psi)$ across their membranes; as the cell loses viability this potential difference falls, allowing the accumulation of anionic fluorochromes within the cell.

A viable culture of $G$. intestinalis and a culture that had been incubated at $4{ }^{\circ} \mathrm{C}$ for $18 \mathrm{~h}$ to kill the trophozoites were incubated with calcofluor white. In the viable culture very few cells stained with the fluorochrome; only the rounded swollen cells took it up. After incubation at $4{ }^{\circ} \mathrm{C}$ for $18 \mathrm{~h}$, the proportion of cells that stained with the fluorochrome had dramatically increased, indicating that this fluorochrome is also an indicator of viability in Giardia (Fig. 2c, d).
Incubation of $G$. intestinalis with whole garlic preparation (Fig. 2f) and with allyl alcohol facilitated the uptake of the fluorochrome. This is indicative that the biocide actively collapses the transmembrane electrochemical potential. As with observations made under visible light, the numbers of cells decreased and the numbers of immotile and swollen cells increased with increasing concentration of biocide; damage was further exemplified by an increase in the number of fluorescent cells. Allyl alcohol brought about this change more rapidly, and at lower concentrations, with all of the cells becoming non-viable at concentrations $>10 \mu \mathrm{g} \mathrm{ml}^{-1}$ (Fig. 2g, h).

\section{Scanning electron microscopy}

Visualization of the surface topography of the trophozoites showed the following distinct features. The trophozoite is pyriform in shape, with a broad anterior and tapered posterior. The dorsal surface (Fig. 3a) is pitted and has many small protuberances. Three of the four pairs of flagella are visible; the anterior flagella emerge at the broadest point of the cell, the posteriolateral flagella emerge just anterior to the posterior tip of the organism and the caudal flagella emerge at the extreme posterior.

The ventral surface has many more distinguishing features, the most dominant of which is the ventral disc, which covers the anterior two-thirds of the trophozoite. It is composed of a spiral of microtubules of uniform period, the spiral of which can just be seen externally. This cytoskeletal component acts as a sucking disc allowing attachment to the microvillous surface of the intestinal mucosa. The edge of the disc is very rigid and contains many of the well-characterized contractile proteins actin, actinin and myosin. This rigid edge is called the lateral crest and it is overlaid by a mobile cytoplasmic lip, the ventrolateral flange, which is thought to play a secondary part in attachment. It interdigitates with the microvilli to form two lateral channels about the ventral disc. Flagellar movement then creates a hydrodynamic force, which assists attachment. At the posterior of the disc is a small ventral groove from which the fourth pair of flagella, the ventral flagella, emerges. Overall this surface is highly organized and shows a high degree of rigidity (Fig. 3b).

Incubation of $G$. intestinalis with $1.0 \mathrm{mg}$ whole garlic preparation $\mathrm{ml}^{-1}$ (Fig. 3c) induced a change in this surface topography. Firstly, the flagella could not be seen emerging from the body; as described below, transmission electron microscopy showed that this was due to the internalization of the flagella in response to

Fig. 2. Control and test cultures viewed under either transmitted or ultraviolet light, using calcofluor white as a

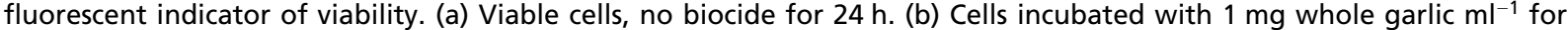
$24 \mathrm{~h}$. (c) Viable culture, stained with calcofluor white after $24 \mathrm{~h}$ growth. (d) Culture incubated at $4{ }^{\circ} \mathrm{C}$ for $18 \mathrm{~h}$ to kill cells stained with calcofluor white. (e) Control culture without biocide stained with calcoflour white shows some non-viable cells. (f) Cells incubated with $1 \mathrm{mg}$ whole garlic $\mathrm{ml}^{-1}$ for $24 \mathrm{~h}$ show a decrease in cell numbers and an increase in uptake of the fluorophore. $(\mathrm{g}, \mathrm{h})$ Cells incubated with 5 and $10 \mu \mathrm{g}$ allyl alcohol $\mathrm{ml}^{-1}$, respectively. $\mathrm{V}$, viable cell. Bars: $75 \mu \mathrm{m}(\mathrm{a})$; $200 \mu \mathrm{m}(\mathrm{c}, \mathrm{d}) ; 50 \mu \mathrm{m}(\mathrm{b}, \mathrm{e}, \mathrm{f}, \mathrm{g}, \mathrm{h})$. 

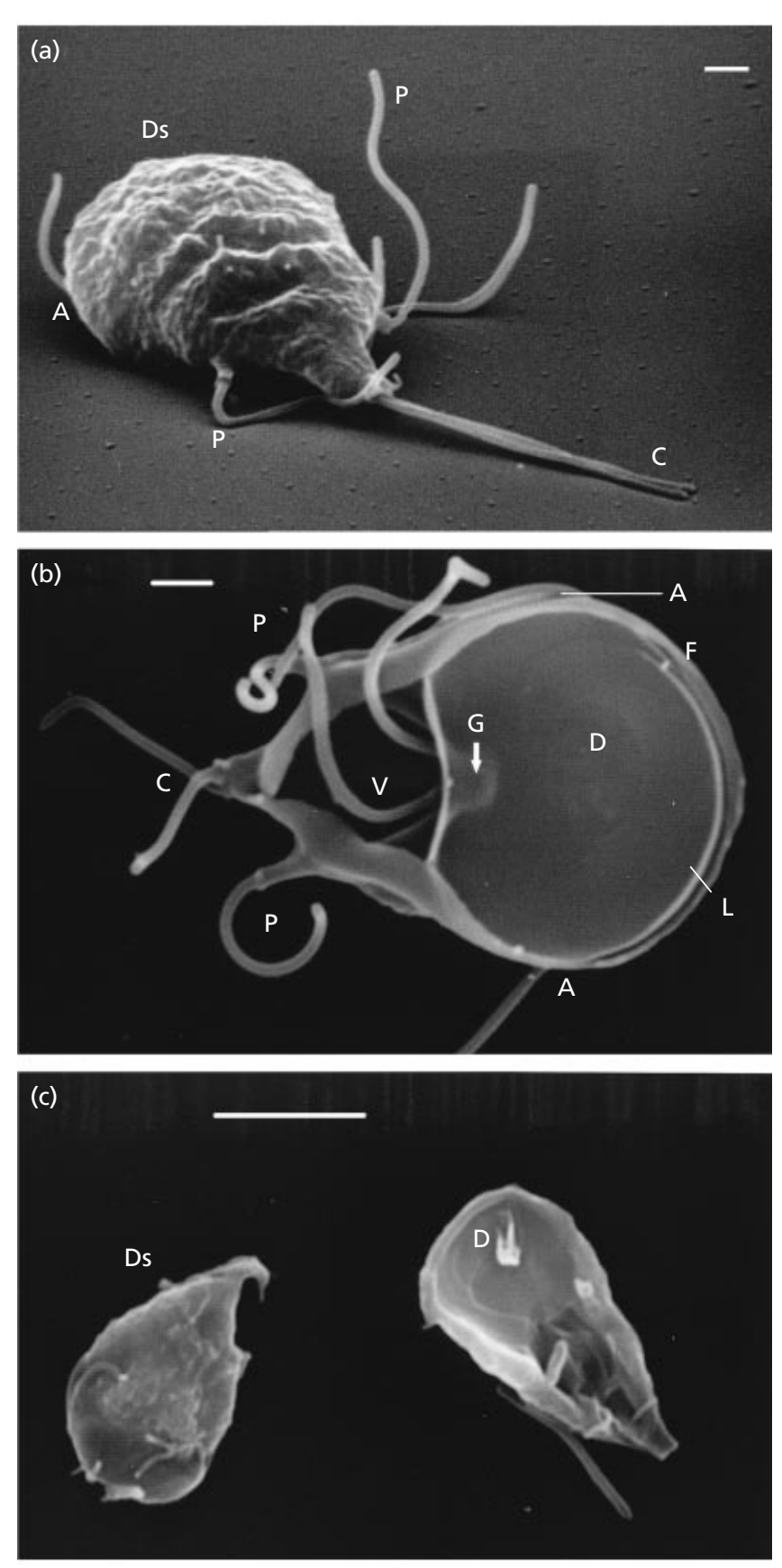

Fig. 3. Scanning electron micrographs of $G$. intestinalis. (a) Dorsal surface; (b) ventral surface; (c) cells incubated with $1 \mathrm{mg}$ whole garlic $\mathrm{ml}^{-1}$ for $24 \mathrm{~h}$. Ds, dorsal surface, $\mathrm{P}$, posteriolateral flagella, C, caudal flagella, A, anterior flagella, V, ventral flagella, G, ventral groove, $D$, ventral disc, $L$, lateral crest; $F$, ventrolateral flange. Bars: $1 \mu \mathrm{m}(\mathrm{a}, \mathrm{b}) ; 5 \mu \mathrm{m}(\mathrm{c})$.

the biocide. Internalization of flagella in response to external stresses has been noted previously with trichomonads (Taucher et al., 1996). Secondly, the rigid structure of the ventral disc and its lateral crest and flange appeared to have been compromised. The structure was no longer as organized, apparently having lost its rigidity.

\section{Transmission electron microscopy}

Control micrographs showed the main distinguishing features of the trophozoite. These are described in the accompanying paper (Lloyd et al., 2000); see Fig. 6(a, b) of that paper. Incubation of cells with garlic affected the internal organization. With $0 \cdot 1 \mathrm{mg}$ garlic $\mathrm{ml}^{-1}$, most of the cells retained their pyriform structure and all of the major components were still in their normal locations. The most noticeable change was an increase in size and number of the peripheral vesicles (Fig. 4a, b). When the concentration of the biocide was increased to $0.25 \mathrm{mg} \mathrm{ml}^{-1}$, a noticeable change in the pyriform structure was evident together with a degree of fragmentation within the cytoplasm (not shown). At $1.0 \mathrm{mg} \mathrm{ml}^{-1}$, pyriform cells were rare (Fig. 4c). Flagella were internalized into large vacuoles. The peripheral vesicles were numerous and distended and covered every external border, except where there were disc microribbons. The main components, nuclei and axonemes, were not located at their original positions, being displaced throughout the cytoplasm. The most noticeable feature was the overexpression of disc proteins located within the cytoplasm, some cells appearing to have three discs (Fig. 4c).

Incubation of $G$. intestinalis with allyl alcohol resulted in the same morphological changes as observed for incubation with whole garlic extract; however, incubation with allyl mercaptan up to $20 \mu \mathrm{g} \mathrm{ml}^{-1}$ only resulted in increasing numbers of distended vesicles and cell swelling.

\section{DISCUSSION}

The results presented in this paper support the growing amount of evidence for the antigiardial activity present in garlic. This new effective alternative treatment is extremely important in today's climate, where species are becoming resistant and there is a resurgence in the use of natural alternative therapies, instead of synthetic pharmaceuticals that often have severe side effects.

For many years allicin was considered the active ingredient of allium treatments, although pharmacokinetic evidence suggests that the observed effect of allicin in vitro is unlikely to be mimicked in vivo, as the half-life of the molecule in biological tissues is minutes (Koch, 1996). Increasingly, investigators are turning to the metabolic breakdown products of the thiosulphinates, which reach high systemic levels, as effector molecules (Lawson \& Wang, 1993; Taucher et al., 1996).

Head-space gas chromatography of exhaled air (Taucher et al., 1996; Laasko et al., 1988), and urine, blood and tissue sample analysis (Koch, 1996), examined after ingestion of garlic, show that the levels of these smaller metabolites are more significant than those of allicin. Allyl alcohol is present in exhaled air after ingestion of all garlic products, the highest concentration being after ingestion of freeze-dried garlic tablets (Laasko et al., 1988). This suggests that the manufacturing process increases the level of this component. 

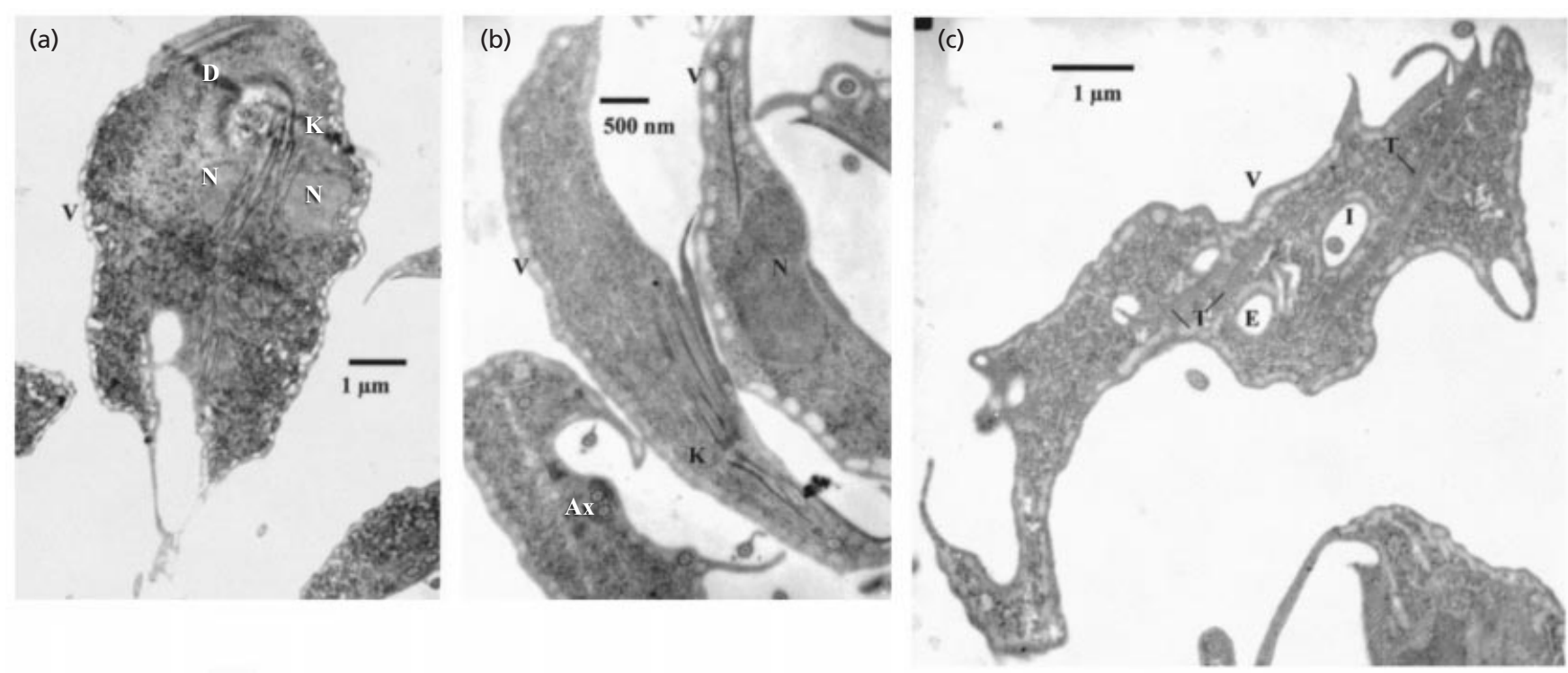

Fig. 4. Transmission electron micrographs of G. intestinalis. See Lloyd et al. (2000) (accompanying paper) for micrographs of control cells. (a) Ventral section through a trophozoite incubated with $0.1 \mathrm{mg}$ whole garlic $\mathrm{ml}^{-1}$. (b) Vertical and horizontal sections through trophozoites incubated with $0.1 \mathrm{mg}$ whole garlic $\mathrm{ml}^{-1}$. (c) Trophozoite incubated with $1 \mathrm{mg}$ whole garlic $\mathrm{ml}^{-1}$ for $24 \mathrm{~h}$. N, nuclei; $\mathrm{K}$, kinetosomal complex; D, ventral disc microribbons; Ax, axonemes; $\mathrm{V}$, peripheral vesicles; E, vacuoles; T, fragmented discs; I, internalized flagella.

Allyl mercaptan is present at high levels in the blood and urine.

Allyl alcohol is produced from garlic in two ways: firstly by a self-condensation reaction of allicin and secondly by the reaction between alliin, the precursor of allicin, and water (Lawson, 1996). Allyl mercaptan, however, is a breakdown product of allyl sulphides and disulphides, of ajoene, and of the reaction product of allicin with cysteine, which abounds in the blood and other biological tissues. Although these metabolites of garlic are effective against Giardia, the antimicrobial data must be balanced with toxicological data before their use as therapeutic compounds can be established. Recent studies have shown that allyl alcohol up to $100 \mu \mathrm{l}$ is not hepatotoxic in rats (Tygstrup et al., 1997). Administration of allyl alcohol with garlic oil was protective against allyl-alcohol-induced toxicity (Kim et al., 1995). Allyl mercaptan was not cytotoxic at levels $<100 \mu \mathrm{g} \mathrm{ml}^{-1}$ in HepG2 cells (Xu \& Cho, 1999).

The efficacy of a whole garlic preparation as an antigiardial was noted in an in vivo study (Soffar \& Mokhtar, 1991); in vitro analysis may lead to the establishment of a mechanism of action. In vitro incubation of $G$. intestinalis with whole garlic preparation results in a loss of flagellar movement and cell motility, detachment of organisms from the reaction vessel wall and loss of osmoregularity, resulting in cell swelling and collapse of the electrochemical membrane potential. Electron microscopy indicates that the ventral disc has been compromised and the flagella are internalized; both of these organelles are responsible for the attachment of cells in vitro and in vivo. Overexpression of disc proteins may indicate that garlic exerts an effect on nucleic acids either directly or indirectly via transcription factors. We also see a loss in caudal-dorsal and posterior-anterior axis positioning of organelles, and a dramatic increase in the size and number of peripheral vesicles.

This work indicates the efficacy of garlic as an antigiardial and the resulting morphological changes, but what is the mechanism of action? Garlic extracts rapidly diffuse through biological membranes, making them fragile and increasing their permeability to small molecules (Bogin, 1973). This property cannot be attributed to allicin as this compound has been shown not to compromise membranes (Miron et al., 2000). The ready permeability to garlic compounds suggests that internal action against nucleic acids, transcription factors and enzymes is the most likely mode of action.

Garlic is also thought to act in vivo by stimulating the production of nitric oxide synthase (NOS) (Das et al., 1995). NO is thought to be the ultimate mediator of immune function within the cell and has been shown to be cytotoxic to Giardia (Fernandes \& Assreuy 1997; Eckmann et al., 2000). Giardia compromise the production of epithelial NOS by competing with the enzyme for arginine, the NO precursor (Eckmann et al., 1998). Garlic has been shown to stimulate the formation of calcium-dependent NOS in placental villous tissue and platelets (Das et al., 1995). However, the mechanism for activation does not appear to be replenishment of arginine, or stimulation by allicin, ajoene or any alliinderived metabolite, as the activation is not heat labile (Das et al., 1996). Allicin and ajoene inhibit calciumindependent NOS (iNOS) production in macrophages. Allicin and ajoene are thought to act by decreasing 
iNOS mRNA either directly by decreasing mRNA stability or through $\mathrm{NF} \kappa \mathrm{B}$, the transcription factor responsible for the production of NOS (Dirsch et al., 1998). However, their effect on calcium-dependent NOS has not been established. Garlic has been shown to affect the physiology of the gastrointestinal tract. It decreases episodes of diarrhoea by relaxing smooth muscle to decrease peristaltic action (Joshi et al., 1987). This may also indicate a role for $\mathrm{NO}$, the effector of smooth muscle relaxation.

The efficacy of garlic extract as an antigiardial, along with several of its smaller metabolites, has been established and quantified in this study. Further work on the analysis of the quantity of these compounds in the crude, whole garlic preparation is being undertaken to further quantify the action of the extract, and to elucidate its mode of action.

\section{ACKNOWLEDGEMENTS}

Janine C. Harris was jointly funded by Cardiff University and Cultech Biospeciality Products.

\section{REFERENCES}

Bartzatt, R., Blum, D. \& Nagel, D. (1992). Isolation of garlic derived sulphur compounds from urine. Anal Lett 25, 1217-1224.

Berglund, D., Taffs, R. E. \& Robertson, N. P. (1987). A rapid analytical technique for flow cytometric analysis of cell viability using calcofluor white M2R. Cytometry 8, 421-426.

Bingham, A. K., Jarroll, E. L. \& Meyer, E. A. (1979). Giardia sp.: physical factors of excystation in vitro and excystation vs eosin exclusion as determinants of viability. Exp Parasitol 47, 284-291.

Bogin, E. (1973). Studies on the effect of antibacterial compounds from garlic on biological membranes. Proc Congr Biochem 9, 271.

Calzada, F., Alanis, A. D., Meckis, M., Contreras, A. \& CedilloRivera, R. (1998). In vitro susceptibility of Entamoeba histolytica and Giardia lamblia to some medicinal plants used by the people of Southern Mexico. Phytother Res 12, 70-72.

Das, I., Khan, N. S. \& Sooranna, S. R. (1995). Potent activation of nitric oxide synthase by garlic: a basis for its therapeutic applications. Curr Med Res Opin 13, 257-263.

Das, I., Hirani, J. \& Sooranna, S. (1996). Arginine is not responsible for the activation of nitric oxide synthase by garlic. J Ethnopharmacol 53, 5-9.

Davidson, R. A. (1990). Treatment of giardiasis: the North American perspective. In Human Parasitic Diseases, vol. III, Giardiasis, pp. 325-334. Edited by E. A. Meyer. Amsterdam: Elsevier.

Davies, R. B. \& Hibler, C. P. (1979). Animal reservoirs and cross species transmission of Giardiasis. In Waterborne Transmission of Giardiasis, pp. 104-126. Edited by W. Jakubowski \& J. C. Hoff. Cincinnati: Environmental Protection Agency.

Dirsch, V. M., Kiemer, A. K., Wagner, H. \& Vollmar, A. M. (1998). Effect of allicin and ajoene, two compounds of garlic, on inducible nitric oxide synthase. Atherosclerosis 139, 333-339.

Eckmann, L., Laurent, F., Gillin, F. D. \& Kagnoff, M. F. (1998). Giardia lamblia infection of human intestinal cell cultures inhibits epithelial nitric oxide production. Gastroenterology 114, G3977.

Eckmann, L., Laurent, F., Langford, T. D., Hetsko, M. L., Smith, J. R., Kagnoff, M. F. \& Gillin, F. D. (2000). Nitric oxide production by human intestinal epithelial cells and competition for arginine as potential determinants of host defense against the lumendwelling pathogen Giardia lamblia. J Immunol 164, 1478-1487.

Edwards, M. R., Gilroy, F. V., Jiminez, M. B. \& O'Sullivan, W. J. (1989). Alanine is a major end product of metabolism by Giardia lamblia: a proton nuclear magnetic resonance study. Mol Biochem Parasitol 37, 19-26.

Fenwick, G. R. \& Hanley, A. B. (1985). The genus Allium, part 3. Crit Rev Food Sci Nutr 22, 1-73.

Fernandes, P. D. \& Assreuy, J. (1997). Role of nitric oxide and superoxide in Giardia lamblia killing. Braz J Med Biol Res 30, 93-99.

Fischer, J. M. C., Peterson, C. A. \& Bols, N. C. (1985). A new fluorescent test for cell vitality using calcofluor white M2R. Stain Technol 60, 69-79.

Friedman, G. D. (1980). Cancer after metronidazole. N Engl J Med 302, 519.

Joshi, D. J., Dikshit, R. K. \& Mansuri, S. M. (1987). Gastrointestinal actions of garlic oil. Phytother Res 1, 140-141.

Kiesewetter, H., Jung, F., Jung, E. M., Mroweitz, C., Koscrelny, J. \& Wenzel, E. (1993). Effect of garlic on platelet aggregation in patients with increased risk of juvenile ischaemic attacks. Eur $J$ Clin Pharmocol 45, 333-336.

Kim, S. G., Nam, S. Y., Chung, H. C., Hong, S. Y. \& Jung, K. H. (1995). Enhanced effectiveness of dimethyl-4,4'-dimethyl$5,6,5^{\prime}, 6^{\prime}$-dimethylene dioxyphenyl-2,2'-dicarboxylate in combination with garlic oil against experimental hepatic injury in rats and mice. J Pharm Pharmacol 47, 678-682.

Koch, H. P. (1996). Biopharmaceutics of garlic's effective compounds. In Garlic. The Science and Therapeutic Application of Allium sativum L. and Related Species, 2nd edn, pp. 213-220. Edited by H. P. Koch \& L. D. Lawson. Baltimore: Williams \& Wilkins.

Laasko, I., Seppänen-Laasko, T., Hiltunen, R., Muller, B., Jansen, H. \& Knobloch, K. (1988). Volatile garlic odour components: gas phases and adsorbed exhaled air analysed by head-space gas chromatography mass spectrometry. Planta Med 55, 257-261.

Lawson, L. D. (1996). The composition and chemistry of garlic cloves and processed garlic. In Garlic. The Science and Therapeutic Application of Allium sativum L. and Related Species, 2nd edn, pp. 37-107. Edited by H. P. Koch \& L. D. Lawson. Baltimore: Williams \& Wilkins.

Lawson, L. D. \& Wang, Z. J. (1993). Pre-hepatic fate of the organosulfur compounds derived from garlic (Allium sativum). Planta Med 59, A688.

Leighton, T., Ginther, C., Fluss, L., Harter, W. K., Cansado, J. \& Notario, N. (1993). Molecular characterisation of quercitin and quercitin glycosides in Allium vegetables: their effects on malignant cell transformation. ACS Symp Ser 507, 220-238.

Lengerich, E. J., Addiss, D. G. \& Juranek, D. D. (1994). Severe giardiasis in the US. Clin Infect Dis 18, 760-763.

Lloyd, D., Harris, J. C., Maroulis, S., Biagini, G. A., Wadley, R. B., Turner, M. P. \& Edwards, M. R. (2000). The microaerophilic flagellate Giardia intestinalis: oxygen and its reaction products collapse membrane potential and cause cytotoxicity. Microbiology 146, 3109-3118.

Lun, Z. R., Burri, C., Menzinger, M. \& Kaminsky, R. (1994). Antiparasitic activity of diallyl trisulphide (dasuansu) on human and animal pathogenic protozoa (Trypanosoma sp., Entamoeba histolyica and Giardia lamblia) in vitro. Ann Soc Belge Med Trop 74, 51-59. 
Majewska, A. C., Kasprzak, W., De Jonckheere, J. F. \& Kaczmarek, E. (1991). Heterogeneity in the sensitivity of stocks and clones of Giardia to metronidazole and ornidazole. Trans R Soc Trop Med Hyg 85, 67-69.

Meyer, E. A. (1976). Giardia lamblia: isolation and axenic cultivation. Exp Parasitol 39, 301-310.

Milner, J. A. (1996). Garlic: its anticarcinogenic and antitumorigenic properties. Nutr Rev 54, S82-S86.

Mirelman, D., Monheit, D. \& Varon, S. (1987). Inhibition of growth of Entamoeba histolyica by allicin, the active principle of garlic extract (Allium sativum). J Infect Dis 156, 243-244.

Miron, T., Rabinkov, A., Mirelman, D., Wilchek, H. \& Weiner, L. (2000). The mode of action of allicin: its ready permeability through phospholipid membranes may contribute to its biological activity. Biochim Biophys Acta 1463, 20-30.

Sharma, V. D., Sethi, M. S., Kumar, A. \& Rarotra, J. R. (1977). Antibacterial property of Allium sativum Linn.: in vivo and in vitro studies. Indian J Exp Biol 15, 466-468.

Shukry, S., Zak, A. M., Dupont, H. L., Shoukry, I., Tagi, M. el \& Hamed, S. (1986). Detection of enteropathogens in fatal and potentially fatal diarrhea in Cairo, Egypt. Clin Microbiol 24, 959-962.

Smith, J. J. \& McFeters, G. A. (1997). Mechanisms of INT (2-(4iodophenyl)-3-(-4 nitrophenyl)-5-phenyl tetrazolium chloride and CTC (5-cyano-2,3 ditolyl tetrazolium chloride) reduction in Escherichia coli K-12. J Microbiol Methods 29, 161-175.
Soffar, S. A. \& Mokhtar, G. M. (1991). Evaluation of the antiparasitic effect of aqueous garlic (Allium sativum) extract in hymenolepiasis nana and giardiasis. J Egypt Soc Parasitol 21, 497-502.

Taucher, J., Hansel, A., Jordan, A. \& Lindinger, W. (1996). Analysis of compounds in human breath after ingestion of garlic using proton-transfer-reaction mass spectrometry. J Agric Food Chem 44, 3778-3782.

Tygstrup, N., Jensen, S. A., Krog, B. \& Dalhoff, K. (1997). Expression of liver functions following sub-lethal and non-lethal doses of allyl alcohol and acetaminophen in the rat. J Hepatol 27, 156-162.

Wright, C. W., Melwani, S. I., Phillipson, J. D. \& Warhurst, D. C. (1992). Determination of anti-giardial activity in vitro by means of a soluble formazan production. Trans $\mathrm{R}$ Soc Trop Med Hyg 86, 517-519.

Xu, S. \& Cho, S. B. H. (1999). Allyl mercapten, a major metabolite of garlic compounds, reduces cellular cholesterol synthesis and its secretion in Hep-G2 cells. J Nutr Biochem 10, 654-659.

Yamada, Y \& Azuma, K. (1977). Evaluation of the in vitro antifungal activity of allicin. Antimicrob Agents Chemother 11, 743-749.

Received 2 June 2000; revised 7 August 2000; accepted 21 August 2000. 